\title{
CORRIGENDUM
}

\section{PD.1. Blood pressure maintenance in MO25 $\beta$ has no physiological role in electrolyte homeostasis or systemic blood pressure maintenance in the mouse}

K Siew, P de los Heros, DR Alessi and KM O'Shaughnessy

Journal of Human Hypertension (2014) 28, 342; doi:10.1038/jhh.2013.120

Correction to: Journal of Human Hypertension (2013) 27, 635-655; doi:10.1038/jhh.2013.72

Since the publication of the above paper, the authors have amended the title of this paper to:

'PD.1. MO25 $\beta$ has no physiological role in electrolyte homeostasis or systemic blood pressure maintenance in the mouse'. The 'Blood pressure maintenance in' at the beginning was incorrectly added. 